\title{
ANALISIS PENGARUH KOMITMEN ORGANISASI DAN KEPEMIMPINAN TERHADAP KINERJA KARYAWAN DENGAN KEPUASAN KERJA SEBAGAI VARIABEL INTERVENING (Studi pada PT. Madu Baru Bantul Yogyakarta)
}

\author{
Camela Ikey Badhoeg Dadie*, Rini Nugraheni' ${ }^{1}$ \\ melaikey@gmail.com \\ Jurusan Manajemen Fakultas Ekonomika dan Bisnis Universitas Diponegoro \\ Jl. Prof. Soedharto SH Tembalang, Semarang 50239, Phone: +622476486851
}

\begin{abstract}
This research is motivated by the presence of problems of the many employees who left the company at PT Madu Baru Bantul, Yogyakarta. Moreover, according to the pre-survey interviews that have been done, there is a lack of communication between the leaders with employees. Objective of this study was to analyze the influence of organizational commitment, leadership, employee performance, and job satisfaction as intervening variables in PT Madubaru Bantul Yogyakartace.

Method of analysis of the data used in this research is descriptive and quantitative. The samples in this study were employees of PT Madubaru amounted to 77 people. Data collection was carried out by using a questionnaire that has been tested for validity and reliability. Data analysis method was using classic assumption test, path analylisis, as well as the coefficient of determination.

Descriptive analysis shows that organizational commitment, leadership, job satisfaction and employee performance was moderate. Based on the results of multiple linear analysis and test of Sobel test indicates that organizational commitment, leadership, positive influence on employee performance and job satisfaction mediate organizational commitment and leadership on employee performance. The coefficient of determination shows that the work satifaction of PT Madubaru Bantul Yogyakarta are influenced by organizational commitment, leadership and job satisfaction by 32.o\%, while the remaining $68,0 \%$ are influenced by other variables in which the research did not examined in this study. The coefficient of determination shows that the employees performance of PT Madubaru Bantul Yogyakarta are influenced by organizational commitment, leadership and job satisfaction by 47,7\%, while the remaining $52,3 \%$ are influenced by other variables in which the research did not examined in this study
\end{abstract}

Keywords : organizaitonal commitment, leadership, work satisfaction, and employees performance 


\section{PENDAHULUAN}

Sumber daya manusia sebagai sumber daya yang sangat penting di dalam suatu organisasi. Organisasi akan lebih maju dan berkembang apabila mempunyai tenaga kerja yang handal, dan mampu dijadikan partner kerja oleh pimpinannya dalam menjalankan tugas yang menjadi bagiannya masing-masing. Tenaga kerja dan pimpinan harus saling mendukung, bekerjasama, saling menghargai, juga saling mengerti apa yang menjadi hak dan kewajibannya masing-masing. Perusahaan menggunakan berbagai macam cara untuk mencapai kinerja yang tinggi. Kinerja yang tinggi sangat tergantung pada manusia sebagai faktor yang penting dibanding faktor-faktor lainnya.

Kinerja merupakan suatu prestasi atau tingkat keberhasilan yang dicapai oleh karyawan dalam melaksanakan pekerjaan pada suatu periode tertentu. Kinerja juga dapat diartikan sebagai suatu prestasi yang dicapai dalam melaksanakan pelayanan kepada masyarakat dalam suatu periode. Peningkatan kinerja tidak dapat terwujud apabila tidak ada pengelolaan atau manajemen yang baik, yang dapat mendorong upaya-upaya institusi untuk meningkatkan kinerja. Pangastuti dalam (Mahmudi, 2005) mengungkapkan bahwa usaha-usaha manajemen kinerja ditujukan untuk mendorong kinerja dalam mencapai tingkat tertinggi organisasi. Lebih lanjut, Hasibuan (2007) menyatakan kinerja merupakan perwujudan kerja yang dilakukan oleh karyawan yang biasanya dipakai sebagai dasar penilaian terhadap karyawan atau organisasi. Kinerja yang baik merupakan langkah untuk tercapainya tujuan organisasi. Sehingga perlu diupayakan usaha untuk meningkatkan kinerja. Robertson dalam (Mahmudi, 2005) mengungkapkan bahwa pengukuran kinerja merupakan suatu proses penilaian kemajuan pekerjaan terhadap pencapaian tujuan dan sasaran yang telah ditentukan, termasuk informasi atas efisiensi penggunaan sumber daya dalam menghasilkan barang dan jasa, kualitas barang dan jasa, perbandingan hasil kegiatan dengan target, dan efektivitas tindakan dalam mencapai tujuan.

Sistem pengukuran kinerja diperlukan untuk mengetahui pencapaian organisasi atas tujuan dan misi organisasi/program. Sistem pengukuran kinerja dijabarkan dalam indikator-indikator kinerja yang terdapat dalam desain pengukuran kinerja. Kinerja akan menggambarkan tingkat pencapaian pelaksanaan suatu kegiatan, program, dan kebijaksanaan dalam mewujudkan sasaran, tujuan, misi, dan visi unit kerja tersebut. PT. Madu Baru Bantul D.I Yogyakarta sebagai sebuah perusahaan memiliki perencanaan kinerja guna menentukan bagaimana kinerja harus diukur, mengenali dan merencanakan cara mengatasi kendala, serta mencapai pemahaman bersama tentang pekerjaan. Sehubungan dengan pemaparan diatas, yang menjadi obyek penelitian ini adalah PT Madu Baru, Bantul. Perusahaan ini adalah satusatunya pabrik gula di propinsi Daerah Istimewa Yogyakarta yang mengemban tugas untuk mensukseskan program pengadaan pangan Nasional, khususnya Gula Pasir. Sebagai Perusahaan padat karya banyak menampung tenaga kerja dari Propinsi Daerah Istimewa Yogyakarta. Perusahaan ini terletak di Desa Padokan, Kelurahan Tirtonirmolo, Kecamatan Kasihan, Kabupaten Bantul, Propinsi daerah Istimewa Yogyakarta. Berikut gambaran kinerja karyawan Madu Baru Bantul D.I Yogyakarta dari tahun 2013 sampai dengan tahun 2014. 
Tabel 1.1

Tabel Penilaian Kinerja Karyawan PT. Madu Baru Bantul D.I Yogyakarta Tahun 2013 - 2014

\begin{tabular}{clcccc}
\hline No & \multicolumn{1}{c}{ Bagian } & B & Bahun 2013 & \multicolumn{2}{c}{ Tahun 2014 } \\
& & 28 & 0 & 23 & 0 \\
\hline 1 & SDM \& Umum & 13 & 1 & 16 & 1 \\
2 & Akuntansi \& Keuangan & 2 & 0 & 1 & 0 \\
3 & Pemasaran & 2 & 0 & 0 & 0 \\
4 & SPI & 40 & 8 & 29 & 5 \\
5 & Tanaman & 11 & 0 & 2 & 1 \\
6 & T \& A & 84 & 0 & 76 & 0 \\
7 & Instalasi & 5 & 2 & 4 & 2 \\
8 & Pabrikasi PG & 8 & 1 & 9 & 0 \\
9 & Pabrikasi SP & 193 & 12 & 160 & 9 \\
10 & Jumlah & 67,48 & 4,20 & 53,69 & 3,02 \\
\hline \multicolumn{2}{c}{ Persentase } & \multicolumn{3}{c}{}
\end{tabular}

Sumber : PT. Madu Baru Bantul, 2014

Keterangan :

B : Baik

BS : Baik Sekali

Berdasarkan tabel 1.1 dapat diketahui bahwa mayoritas karyawan yang bekerja di PT. Madu Baru Bantul mendapatkan nilai B pada tahun 2013 sebanyak 193 orang yaitu sebesar 67,48\% dan kemudian jumlah karyawan yang mendapatkan nilai B di tahun 2014 mengalami penurunan menjadi sebanyak 160 orang yaitu sebesar 53,69\%.

Sebagai perusahaan yang memiliki banyak tenaga kerja, perusahaan harus berbenah dan mempersiapkan segala konsekuensi yang mungkin terjadi. Diantaranya dengan meningkatkan komitmen organisasi karyawan, memiliki kepemimpinan yang baik, dan menjadikan kepuasan karyawan yang makin tinggi. Komitmen organisasi menjadi perhatian penting dalam banyak penelitian karena memberikan dampak signifikan terhadap perilaku kerja seperti kinerja, kepuasan kerja, absensi karyawan dan juga turnover karyawan. Hasil wawancara penelitian saat penelitian menyatakan bahwa karyawan sudah memiliki loyalitas yang tinggi, tapi terkadang masih menyepelekan dalam pekerjaan. Namun diantara para karyawan tersebut juga ada karyawan yang mengajukan untuk keluar dari perusahaan, hal ini menunjukkan masih adanya permasalahan yang terjadi pada karyawan. Untuk melengkapi mengenai adanya permasalahan pada komitmen karyawan ini, juga mendapatkan data yang diperoleh dari perusahaan tentang jumlah karyawan yang keluar, yang terlihat tingginya data karyawan yang keluar dalam perusahaan.

Tabel 1.2

Data Karyawan Keluar dan Masuk PT. Madu Baru Bantul

\begin{tabular}{cccc}
\hline Tahun & Keluar & Total Karyawan & Persentase Keluar \\
\hline 2012 & 14 & 242 & 5,79 \\
2013 & 19 & 286 & 6,64 \\
2014 & 25 & 298 & 8,39 \\
\hline
\end{tabular}

Sumber : PT. Madu Baru Bantul 
Melihat data jumlah karyawan pada karyawan di PT. Madu Baru Bantul selama tiga tahun terakhir menunjukkan peningkatan, hal ini tentunya dapat mempengaruhi kinerja karyawan. Dengan banyaknya tenaga kerja yang keluar tentunya perusahaan akan kehilangan karyawan yang sudah berpengalaman dan dilain pihak karyawan mendapat karyawan baru yang kemungkinan belum berpengalaman, kondisi ini jelas akan merugikan perusahaan karena dapat menurunkan tingkat produktivitas kerja perusahaan.

Komitmen dalam organisasi akan membuat pekerja memberikan yang terbaik kepada organisasi tempat dia bekerja. Komitmen organisasional merupakan usaha mengindentifikasikan diri dan melibatkan diri dalam organisasi dan berharap tetap menjadi anggota organisasi (Robbin, 2006). Menurut Allen dan Mayer (1990) ada tiga komponen dalam komitmen yaitu: (a) affective (menunjukkan keinginan karyawan untuk melibatkan diri dan mengindentifikasikan diri dengan organisasi karena adanya kesesuian nilai-nilai dalam organisasi). (b) continuance (komitmen yang timbul karena ada kekhawatiran terhadap kehilangan manfaat yang biasa diperoleh dari organisasi) (c) normative (komitmen yang muncul karena karyawan merasa berkawajiban untuk tinggal dalam organisasi). Hasil penelitian Moncreif (1997) mengungkapkan bahwa komitmen karyawan terhadap organisasi yang tinggi akan berpengaruh terhadap kinerja karyawan. Dan Van Scooter (2000) menyatakan bahwa pekerja dengan komitmen yang tinggi akan lebih berorientasi pada kerja, disebutkan pula bahwa pekerja yang memiliki komitmen organisasi tinggi akan cenderung senang membantu dan dapat bekerja sama.

Setelah komitmen organisasi karyawan yang tinggi, faktor penting lainnya adalah kepemimpinan.
Berdasarkan prasurvey wawancara yang telah dilakukan dengan beberapa karyawan yang menjadi perhatian adalah kurangnya perhatian pimpinan pada bawahan dan hubungan yang kurang harmonis yang disebabkan kurang komunikasi antara pimpinan dengan karyawannya. Kondisi ini jika dibiarkan akan menciptakan suasana kerja yang tidak menyenangkan yang akan menggannggu produktifitas kerja. Maka dari itu untuk menciptakan hubungan yang harmonis diperlukan komunikasi antar pimpinan dan bawahan maupun antar sesama karyawan itu sendiri. Proses komunikasi antar pribadi. Dengan adanya perhatian yang telah diberikan pimpinan akan dapat menimbulkan rasa hormat bawahannya. Dalam hal ini terjalin proses komunikasi yang timbal balik yang pada akhirnya dapat meningkatkan produktifitas kerja pegawai. Dengan demikian juga halnya dalam hubungan dengan sesama karyawan itu sendiri. Adanya hubungan yang baik dan harmonis menjadikan adanya suatu kerja sama yang mantap. Karenanya karyawan akan merasa betah dan senang bekerja di lingkungan kantornya, sehingga produktifitas kerja meningkat.

Penelitian tentang pengaruh kepemimpinan terhadap kinerja telah banyak dilakukan, diantaranya Alberto et al (2005) yang menyatakan bahwa kepemimpinan berpengaruh positif kuat terhadap kinerja. Temuan ini memberikan indikasi bahwa kepemimpinan seorang pemimpin sangat berpengaruh terhadap kinerja bawahannya, di samping itu untuk mendapatkan kinerja yang baik diperlukan juga adanya pemberian pembelajaran terhadap bawahannya. Kinerja pegawai tidak lepas dari peran pemimpinnya, menurut Bass (1990) peran kepemimpinan atasan dalam memberikan kontribusi pada karyawan untuk pencapaian kinerja yang optimal dilakukan melalui lima cara, yaitu : (1) 
pemimpin mengklarifikasi apa yang diharapkan dari karyawannya, secara khusus tujuan dan sasaran dari kinerja mereka, (2) pemimpin menjelaskan bagaimana memenuhi harapan tersebut, (3) pemimpin mengemukakan criteria dalam melakukan evaluasi dari kinerja secara efektif, (4) pemimpin memberikan umpan balik ketika karyawan telah mencapai sasaran, dan (5) pemimpin mengalokasikan imbalan berdasarkan hasil yang telah mereka capai.

Selain faktor komitmen organisasi dan kepemimpinan, salah satu hal lain yang penting adalah terciptanya kepuasan kerja anggota organisasi yang bersangkutan. Kepuasan kerja tersebut diharapkan dapat mempengaruhi pencapaian tujuan organisasi yang lebih baik. Kepuasan kerja karyawan adalah salah satu aspek yang dapat meningkatkan kinerja karyawan, sehingga kepuasan kerja karyawan mempengaruhi kinerja unit secara keseluruhan. Kepuasan kerja merupakan salah satu komponen yang mendukung tercapainya produktivitas. Menurut Robbins (2003:101), kepuasan kerja sebagai suatu sikap umum seseorang individu terhadap pekerjaannya. Kepuasan kerja merupakan salah satu aspek yang penting di dalam praktek manajemen sumber daya manusia dan perilaku organisasi. Ini dikarenakan kepuasan kerja dapat mempengaruhi tingkat absensi, perputaran tenaga kerja, semangat kerja, keluhankeluhan dan masalah-masalah personalia vital lainnya (Handoko, 2000:194). Kepuasan kerja yang tinggi sangat diharapkan karena hal itu berkaitan dengan hasil yang positif dan merupakan tanda organisasi yang dikelola dengan baik. Hasil penelitian Noor Arifin (2012) yang menyimpulkan bahwa kepuasan kerja berpengaruh signifikan terhadap kinerja. Cecilia Engko (2008) yang menyimpulkan terdapat pengaruh kepuasan kerja terhadap kinerja.

Berdasarkan data diatas jelas terdapat masalah kinerja karyawan di PT. Madu Baru Bantul yang ditunjukkan dengan adanya penurunan kinerja pada tabel kinerja individu yang dibuktikan oleh turunnya persentase prestasi kinerja individu karyawan dalam dua tahun berturut-turut. Berdasarkan uraian latar belakang di atas, maka penelitian ini akan mengambil judul "Analisis Pengaruh Komitmen Organisasi Dan Kepemimpinan Terhadap Kinerja Karyawan Dengan Kepuasan Kerja Sebagai Variabel Intervening (Studi Pada PT. Madu Baru Bantul, Yogyakarta)".

\section{KERANGKA HIPOTESIS \\ PEMIKIRAN}

Berdasarkan tinjauan dari teori dan penelitian terdahulu, dapat dibuat kerangka pemikiran teoritis tentang faktor-faktor yang berpengaruh terhadap kinerja karyawan melalui variabel intervening kepuasan kerja. Kerangka pemikiran penelitian ini dapat dilihat pada Gambar 1. 
Gambar 1

Kerangka Pemikiran

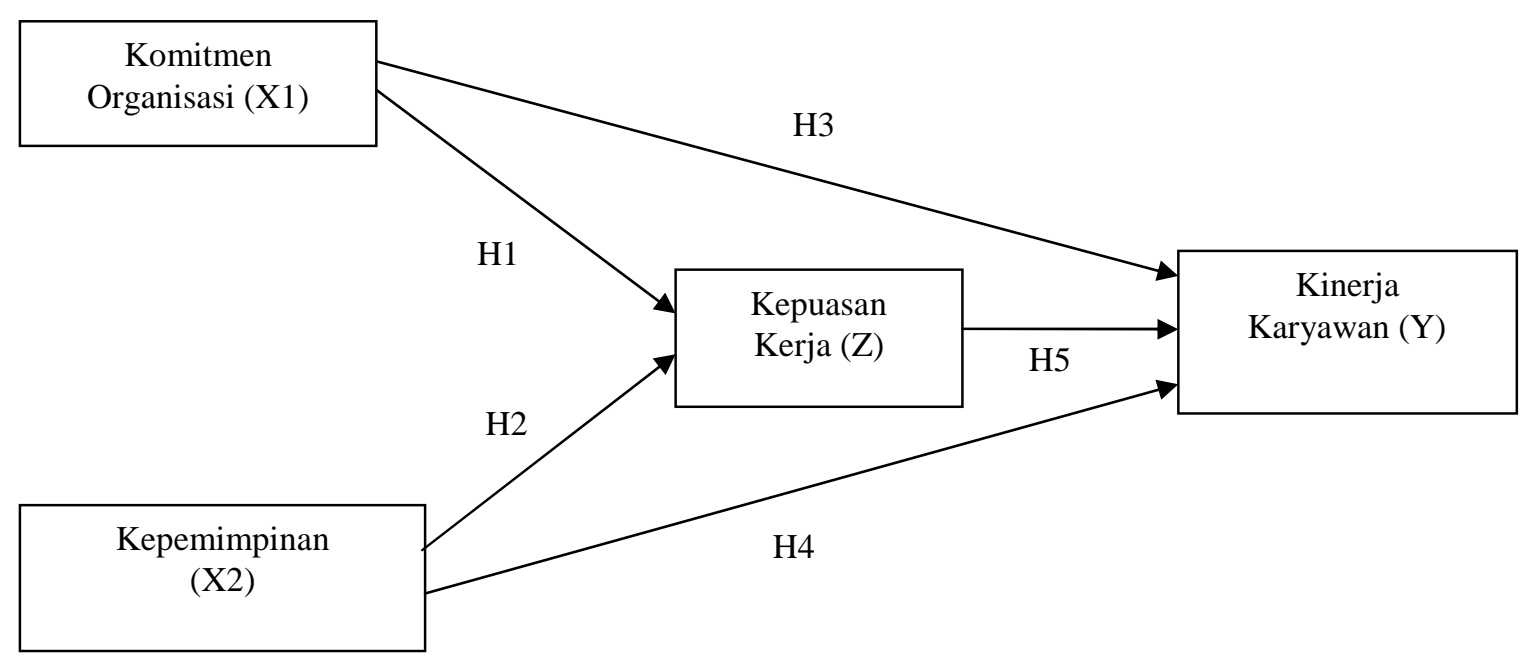

Sumber :Moncreif (1997), Alberto et al (2005), Bass (1990), dan Robins (1996)

METODE PENELITIAN

Populasi dan Sampel Penelitian

Target populasi adalah seluruh seluruh karyawan di PT. Madubaru Bantul D.I Yogyakarta yang berjumlah 329 orang. Sampel yang digunakan pada penelitian ini sebanyak 77 orang karyawan perusahaan. Data dikumpulkan menggunakan kuesioner dengan skala likert $1-5$.

\section{Definisi Operasional Variabel Penelitian}

Komitmen organisasi diukur dengan kriteria : Komitmen organisasi afektif/ affective commitmen : menjadi anggota suatu organisasi karena memang keinginan, Continuance commitment : menjadi anggota suatu organisasi karena kebutuhan, dan Normative commitmen : menjadi anggota suatu organisasi karena merasa berkewajiban (Meyer dan Allen dalam Muchiri, 2002).

Kepemimpinan diukur dengan kriteria : Atasan memberikan tugas yang harus dikerjakan secara langsung, Atasan menekankan pekerjaan secara optimal, Atasan saya menekankan ketepatan waktu terhadap penyelesaian tugas, dan Ketegasan dalam memberikan tugas (Parrek, Udai (1985) dalam Fuad Mas'ud, 2004).

Komitmen organisasi afektif/ affective commitmen : menjadi anggota suatu organisasi karena memang keinginan, Continuance commitment : menjadi anggota suatu organisasi karena kebutuhan, Normative commitmen : menjadi anggota suatu organisasi karena merasa berkewajiban (Meyer dan Allen dalam Muchiri, 2002).

Kepuasan kerja diukur dengan kriteria : Kepuasan dengan gaji, Kepuasan dengan promosi, Kepuasan dengan rekan sekerja, Kepuasan dengan penyelia, dan Kepuasan dengan pekerjaan itu sendiri (Celluci, Anthony J. dan David L. DeVries (1978) dalam Fuad Mas'ud, 2004).

Kinerja diukur dengan kriteria : Kualitas Kerja Karyawan, Kuantitas kerja karyawan, Ketepatan waktu, Ketepatan prosedur (Jansen Onne (2001) dalam Fuad Mas'ud, 2004).

\section{Alat Analisis}

Dalam penelitian ini pengolahan data dilakukan dengan Analisis Jalur/Path yang diselesaikan dengan regresi linier berganda dengan bantuan SPSS 17.0 for windows. 


\section{HASIL PENELITIAN DAN Dengan mayoritas karyawan adalah PEMBAHASAN \\ Identitas Responden \\ Dari total 236 karyawan PT Madubaru Bantul, 77 diantaranya berpartisipasi dalam studi ini. Tabel 1 $84,4 \%$ pria, berusia antara 30 - 40 tahun sebanyak $39 \%$, dan responden dengan pendidikan rata-rata SMA yaitu sebesar $68,8 \%$ serta $40,3 \%$ dari total responden dengan masa kerja di atas 15 tahun.} merangkum karakterisitik responden.

Tabel 3

Karakteristik Responden

\begin{tabular}{|c|c|c|}
\hline Karakteristik & Frekuensi & Persentase \\
\hline \multicolumn{3}{|l|}{ Jenis Kelamin } \\
\hline Pria & 65 & 84,4 \\
\hline Wanita & 12 & 15,6 \\
\hline Jumlah & 77 & 100,0 \\
\hline \multicolumn{3}{|l|}{ Usia } \\
\hline$<30$ tahun & 13 & 16,9 \\
\hline $30-40$ tahun & 30 & 39,0 \\
\hline $41-50$ tahun & 22 & 28,6 \\
\hline$>50$ tahun & 12 & 15,6 \\
\hline Jumlah & 77 & 100,0 \\
\hline \multicolumn{3}{|l|}{ Pendidikan } \\
\hline SMP & 6 & 7,8 \\
\hline SMA & 53 & 68,8 \\
\hline D3 & 3 & 3,9 \\
\hline Sarjana & 15 & 19,5 \\
\hline Jumlah & 77 & 100,0 \\
\hline \multicolumn{3}{|l|}{ Masa Kerja } \\
\hline$<5$ tahun & 16 & 20,8 \\
\hline 5-10 tahun & 18 & 23,4 \\
\hline 11-15 tahun & 12 & 15,6 \\
\hline$>15$ tahun & 31 & 40,3 \\
\hline Jumlah & 77 & 100,0 \\
\hline
\end{tabular}

Sumber : Data primer yang diolah, 2015

Kuesioner dan data yang digunakan telah diuji validitas, reliabilitas, uji asumsi klasik (uji normalitas, uji multikolinearitas, uji heteroskedastisitas I dan II) menunjukkan bahwa data seluruh variabel valid, reliabel, normal, tidak terdapat korelasi atau bebas multikolinearitas dan tidak adanya masalah heterokedastisitas. Setelah asumsi terpenuhi, dilakukan uji regresi linear berganda I dan II.

Tabel 4

Hasil Pengujian Regresi Linear Berganda (Regresi I)

\begin{tabular}{lcccc}
\hline Variabel & $\begin{array}{c}\text { Standardized } \\
\text { Coefficients }\end{array}$ & $\mathbf{t}_{\text {hitung }}$ & Sign. t & Keterangan \\
\hline Konstanta & 1,665 & & & \\
Komitmen organisasi & 0,388 & 3,703 & 0,000 & Signifikan \\
\hline
\end{tabular}




\begin{tabular}{llll}
\hline $\begin{array}{l}\text { Kepemimpinan } \\
\text { Adjusted } \mathrm{R}^{2}=0,320\end{array}$ & 0,297 & 0,006 & Signifikan \\
\hline Variabel dependen : Kepuasan kerja. & & & \\
Sumber : Data Primer yang diolah, 2015 & & \\
\end{tabular}

Model persamaan regresi dapat disimpulkan dari hasil tersebut dalam bentuk persamaan regresi bentuk standart adalah $\mathrm{Y}=0,388 \mathrm{X}_{1}+0,297 \mathrm{X}_{2}$. Dari model tersebut diperoleh bahwa koefisien regresi dari semua variabel adalah positif.

Hipotesis $1 \quad\left(\mathrm{H}_{1}\right)$ : komitmen organisasi memiliki nilai signifikan tsebesar 0,000. Dikarenakan nilai signifikan $\mathrm{t}$ lebih kecil dari nilai signifikan 0,05 atau $(0,000<0,05)$, maka dapat dinyatakan komitmen organisasi berpengaruh signifikan terhadap kepuasan kerja, sehingga hipotesis pertama yang menyatakan terdapat pengaruh antara komitmen organisasi terhadap kepuasan kerja diterima atau terbukti.

Hipotesis $2\left(\mathrm{H}_{2}\right)$ : kepemimpinan memiliki nilai signifikan tsebesar 0,006 . Dikarenakan nilai signifikan $\mathrm{t}$ lebih kecil dari nilai signifikan 0,05 atau $(0,006<$ 0,05), maka dapat dinyatakan kepemimpinan berpengaruh signifikan terhadap kepuasan kerja, sehingga hipotesis kedua yang menyatakan terdapat pengaruh antara kepemimpinan terhadap kepuasan kerja diterima atau terbukti.

Tabel 5

Hasil Pengujian R Square

Model Summary

\begin{tabular}{lrrrr}
\hline Model & $\mathrm{R}$ & $\mathrm{R}$ Square & $\begin{array}{c}\text { Adjusted R } \\
\text { Square }\end{array}$ & $\begin{array}{c}\text { Std. Error of the } \\
\text { Estimate }\end{array}$ \\
\hline 1 &, $581^{\mathrm{a}}$ &, 338 &, 320 &, 4271 \\
\hline
\end{tabular}

a. Predictors: (Constant), KepemimpinanX2, KomitmenOrganisasiX1 Sumber : Data primer yang diolah, 2015

Hasil R square menunjukkan nilai sebesar 0,320 dalam hal ini berarti $32,0 \%$ kepuasan kerja dipengaruhi oleh variabel komitmen organisasi dan kepemimpinan.

Tabel 6

Hasil Pengujian Regresi Linear Berganda (Regresi II)

\begin{tabular}{lcccc}
\hline \multicolumn{1}{c}{ Variabel } & $\begin{array}{c}\text { Standardized } \\
\text { Coefficients }\end{array}$ & $\mathbf{t}_{\text {hitung }}$ & Sign. t & Keterangan \\
\hline Konstanta & 0,908 & & & \\
Komitmen organisasi & 0,210 & 2,102 & 0,039 & Signifikan \\
Kepemimpinan & 0,206 & 2,132 & 0,036 & Signifikan \\
Kepuasan kerja & 0,440 & 4,320 & 0,000 & Signifikan \\
Adjusted $\mathrm{R}^{2}=0,477$ & & & & \\
\hline
\end{tabular}

Variabel dependen : Kinerja

Sumber : Data Primer yang diolah, 2015

Model persamaan regresi dapat disimpulkan dari hasil tersebut dalam bentuk persamaan regresi bentuk standart adalah $\mathrm{Y}=0,210 \mathrm{X}_{1}+0,206 \mathrm{X}_{2}+$ $0,440 Z$. Dari model tersebut diperoleh 
bahwa koefisien regresi semua variabel adalah positif.

Hipotesis $3 \quad\left(\mathrm{H}_{3}\right)$ : Komitmen organisasi memiliki nilai signifikan tsebesar 0,039. Dikarenakan nilai signifikan $\mathrm{t}$ lebih kecil dari nilai signifikan 0,05 atau $(0,039<0,05)$, maka dapat dinyatakan komitmen organisasi berpengaruh signifikan terhadap kinerja, sehingga hipotesis ketiga yang menyatakan terdapat pengaruh antara komitmen organisasi terhadap kinerja karyawan diterima atau terbukti.

Hipotesis $4\left(\mathrm{H}_{4}\right)$ : Kepemimpinan memiliki nilai signifikan tsebesar 0,036. Dikarenakan nilai signifikan t lebih kecil dari nilai signifikan 0,05 atau $(0,036<$ 0,05), maka dapat dinyatakan kepemimpinan berpengaruh signifikan terhadap kinerja, sehingga hipotesis keempat yang menyatakan terdapat pengaruh antara kepemimpinan terhadap kinerja karyawan diterima atau terbukti.

Hipotesis $5 \quad\left(\mathrm{H}_{5}\right)$ : Kepuasan kerja memiliki nilai signifikan tsebesar 0,000 . Dikarenakan nilai signifikan $\mathrm{t}$ lebih kecil dari nilai signifikan 0,05atau $(0,000<0,05)$, maka dapat dinyatakan kepuasan kerja berpengaruh signifikan terhadap kinerja, sehingga hipotesis kelima yang menyatakan terdapat pengaruh antara kepuasan kerja terhadap kinerja karyawan diterima atau terbukti.

Tabel 7

Hasil Pengujian R Square

Model Summary

\begin{tabular}{llrrr}
\hline Model & R & R Square & $\begin{array}{c}\text { Adjusted R } \\
\text { Square }\end{array}$ & \multicolumn{1}{c}{$\begin{array}{c}\text { Std. Error of the } \\
\text { Estimate }\end{array}$} \\
\hline 1 &, $706^{\mathrm{a}}$ &, 498 &, 477 &, 37978 \\
\hline
\end{tabular}

a. Predictors: (Constant), KepuasanKerjaZ, KepemimpinanX2,

KomitmenOrganisasiX1

Sumber : Data primer yang diolah, 2015

Hasil R square menunjukkan nilai sebesar 0,477 dalam hal ini berarti $47,7 \%$ kinerja karyawan dipengaruhi oleh variabel komitmen organisasi dan kepemimpinan, serta kepuasan kerja.

Gambar 2

Diagram Analisis Path

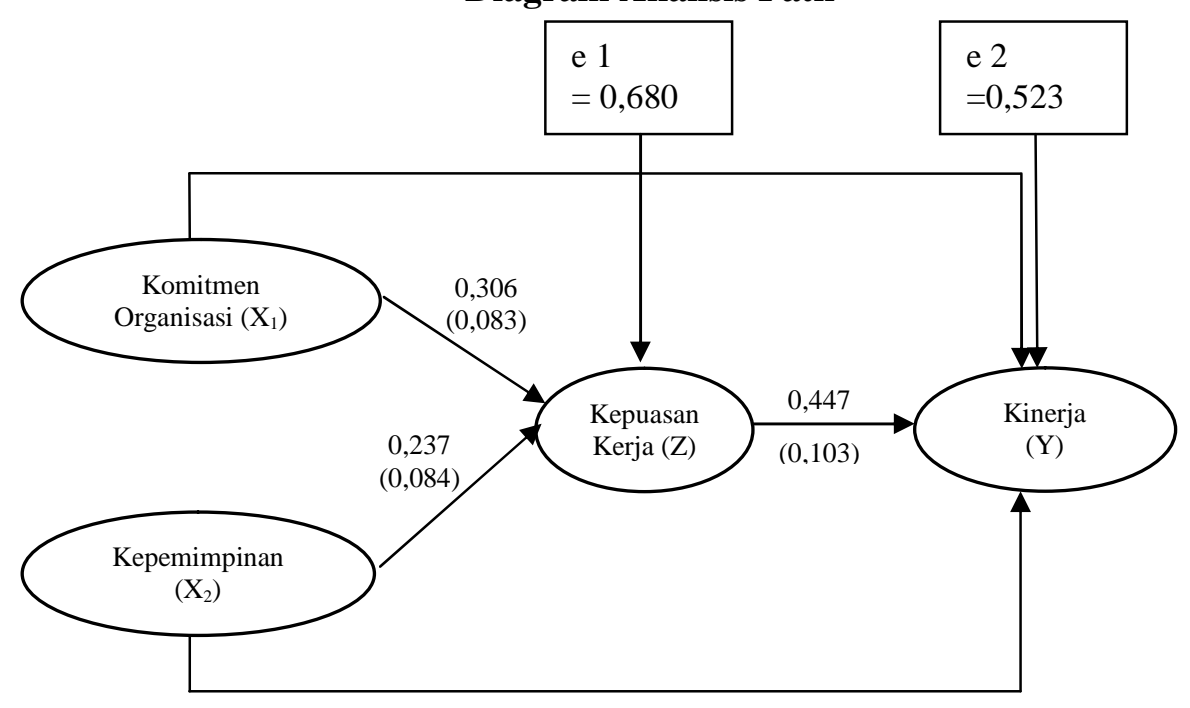


1. Nilai t hitung dan berdasarkan hasil Sobel Test sebesar 2,8097 yaitu lebih besar dari $\mathrm{t}$ tabel 1,96 dengan nilai signifikan 0,000 sehingga sig. $<0,05$ yang berarti bahwa parameter mediasi tersebut positif signifikan. Hal tersebut menunjukkan bahwa kepuasan keja karyawan memediasi pengaruh komitmen organisasi terhadap kinerja karyawan, sehingga hipotesis keenam yang menyatakan terdapat pengaruh komitmen organisasi terhadap kinerja karyawan melalui kepuasan kerja diterima atau terbukti.

2. Nilai t hitung dan berdasarkan hasil Sobel Test sebesar 2,3654 yaitu lebih besar dari t tabel 1,96 dengan nilai signifikan 0,000 sehingga sig. $<0,05$ yang berarti bahwa parameter mediasi tersebut positif signifikan. Hal tersebut menunjukkan bahwa kepuasan keja karyawan memediasi pengaruh kepemimpinan terhadap kinerja karyawan, sehingga hipotesis ketujuh yang menyatakan terdapat pengaruh kepemimpinan terhadap kinerja karyawan melalui kepuasan kerja diterima atau terbukti.

\section{KESIMPULAN \\ KETERBATASAN \\ Kesimpulan}

Kesimpulan yang diperoleh berdasarkan hasil penelitian ini dapat ditunjukkan sebagai berikut :

1. Hipotesis pertama $\left(\mathrm{H}_{1}\right)$ : Komitmen organisasi berpengaruh positif terhadap kepuasan kerja. Hal ini berarti bahwa makin tingginya komitmen organisasi karyawan maka akan semakin tinggi tingkat kepuasan kerja karyawan.

2. Hipotesis kedua $\left(\mathrm{H}_{2}\right)$ : Kepemimpinan berpengaruh positif terhadap kepuasan kerja. Hal ini berarti semakin baik kepemimpinan maka akan semakin tinggi tingkat kepuasan kerja karyawan

3. Hipotesis ketiga $\left(\mathrm{H}_{3}\right)$ : Komitmen organisasi berpengaruh positif terhadap kinerja.Hal ini berarti semakin tingginya komitmen organisasi yang ditunjukkan karyawan dalan perusahaan akan menjadikan kinerja karyawan semakin baik.

4. Hipotesis keempat $\left(\mathrm{H}_{4}\right)$ : Kepemimpinan berpengaruh positif terhadap kinerja. Hal ini berarti semakin baik tingkat kepemimpinan maka akan semakin tinggi kinerja karyawan

5. Hipotesis kelima $\left(\mathrm{H}_{5}\right)$ : Kepuasan kerja berpengaruh positif terhadap kinerja. Hal ini menunjukan semakin tinggi tingkat kepuasan karyawan maka akan semakin tinggi pula tingkat kinerja karyawan.

6. Kepuasan kerja memediasi komitmen organisasi terhadap kinerja karyawan, yang berarti pengaruh langsung komitmen organisasi terhadap kinerja karyawan lebih kecil dibandingkan pengaruh tidak langsung yaitu komitmen organisasi terhadap kinerja karyawan melalui kepuasan kerja karyawan, sehingga kepuasan kerja karyawan dapat berperan sebagai variabel intervening.

7. Kepuasan kerja memediasi pengaruh kepemimpinan terhadap kinerja karyawan, yang berarti pengaruh langsung kepemimpinan terhadap kinerja karyawan lebih kecil dibandingkan pengaruh tidak langsung yaitu kepemimpinan terhadap kinerja karyawan melalui kepuasan kerja karyawan, sehingga kepuasan kerja karyawan dapat berperan sebagai variabel intervening.

\section{Keterbatasan}

Penelitian ini tidak terlepas dari keterbatasan. Karena keterbasatan yang 
ada, hal tersebut dapat dijadikan sebagai bahan perbaikan bagi penelitian selanjutnya. Adapun keterbatasan dari penelitian ini adalah :

1. Pada hasil pengisian kuesioner terutama untuk jenis pertanyaan terbuka masih terdapat beberapa jawaban kosong, sehingga informasi yang diperoleh dalam penelitian ini terbatas.

2. Dalam proses pengisian kuesioner, diperoleh adanya sifat responden sendiri yakni ketakutan dalam menjawab pertanyaan yang diberikan dengan sebenarnya.

Saran

Saran-saran yang dapat diberikan sehubungan dengan hasil analisis pada bab sebelumnya adalah :

1. Bagi Perusahaan :

Berdasarkan hasil analisis mengenai komitmen organisasi, analisis indeks indikator memiliki sedikit pilihan bila ingin meninggalkan organisasi mempunyai nilai yang terendah. Berdasarkan pada rata-rata jawaban responden yang menunjukan nilai kategori sedang. Berkaitan dengan hal tersebut maka pihak perusahaan bisa lebih memperhatikan karyawan dalam hal keinginan untuk tetap di perusahaan atau tidak meninggalkan perusahaan.Dan bagi karyawan yang telah lama bekerja bisa diberikan kenaikan pangkat.

Berdasarkan analisis mengenai kepemimpinan, analisis indeks indikator atasan menekankan tugas yang harus dikerjakan secara langsung dan atasan tegas dalam memberikan tugas mempunyai nilai indeks terendah .Berdasarkan pada rata-rata jawaban responden yang menunjukan nilai kategori sedang Berkaitan dengan hal tersebut maka pihak perusahaan harus memperbaiki kepemimpinannya dalam hal menekankan tugas yang harus dikerjakan secara langsung dan tegas dalam memberikan tugas. Dan mempererat hubungan antara atasan bawahan misalnya diadakan acara Family Gathering atau outbound sehingga dapat terjalin komunikasi yang baik antara atasan dengan karyawan.

Berdasarkan analisis mengenai kepuasan kerja, analisis indeks indikator menikmati bekerja dengan teman-teman sendiri mempunyai nilai indeks terendah. Hal ini berdasarkan pada rata-rata jawaban responden yang menunjukan nilai kategori sedang Berkaitan dengan hal tersebut maka pihak perusahaan harus memperhatikan kepuasan kerja karyawan di pandang dari segi karyawan dalam menikmati pekerjannya dengan teman-teman kerja misal dengan mengadakan outbound sehingga mempererat komunikasi dan silahturahmi antar karyawan.

Berdasarkan analisis mengenai kinerja karyawan, indikator skill/keahlian melebihi rata-rata karyawan lain mempunyai nilai indeks terendah .Hal ini berdasarkan pada rata-rata jawaban responden yang menunjukan nilai kategori sedang. Berkaitan dengan hal tersebut maka pihak perusahaan sebaiknya mengadakan program pelatihan kerja bagi karyawan guna membantu meningkatkan skill/keahlian kerja karyawan.

2. Bagi Penelitian Yang Mendatang Bagi peneliti lain yang ingin melakukan penelitian mengenai kinerja karyawan, model ini dapat dikembangkan dengan menambah variabel lain yang mungkin dapat mempengaruhi kepuasan kerja dan kinerja karyawan, seperti variabel kompensasi, lingkungan kerja, budaya organisasi dan disiplin kerja.

Menggunakan ruang lingkup populasi yang lain, dan 
menggunakan sampel responden yang lebih banyak, sehingga diharapkan hasil penelitian yang akan datang akan lebih spesifik.

\section{REFERENSI}

Algifari. 2000. Analisis Regresi, Teori, Kasus \& Solusi. BPFE UGM, Yogyakarta. Allen, N.J. and Meyer, J.P. 1990, The Measurement and Antecedents of Affective, continuance and Normative Commitment, Journal of Occupational Psychology, 63, 1, pp.1-18.

Amilin, Rosita Dewi. 2008. Pengaruh Komitmen Organisasi Terhadap Kepuasan Kerja Akuntan Publik Dengan Role Stress sebagai Variabel Moderating. JAAI Vol.12. No.1, Juni 2008:13-24.

Arikunto, Suharsimi. 2006, Prosedur Penelitian Suatu Pendekatan Praktik. Jakarta : Rineka Cipta.

As'ad, Moh. 2002. Psikologi Perusahaan, Yogyakarta: Liberty.

Bass, B.M dan Avolio. 1990. "The Implications of Transaksional and Transformational", Team and Organization Development, 4, p.231-273

Cecilia, Engko. 2008. Pengaruh Kepuasan Kerja Terhadap Kinerja Individual Dengan Self Esteem dan Self Efficacy Sebagai Variabel Intervening, Jurnal Bisnis dan Akuntansi, Vol. 10, No. 1, April

Daft, R. L. 2003. Manajemen. Jilid 2, Alih Bahasa : Emil Salim \& Iman Karmawan, Jakarta : Penerbit Erlangga.

Ferdinand, Augusty. 2006. Metode Penelitian Manajemen. Semarang: Badan Penerbit Universitas Diponegoro

Ghozali, Prof. Dr.h. Imam, M.Com,Akt . 2011. Aplikasi Analisis Multivariate Dengan Program IBM SPSS 19 (edisi kelima.) Semarang: Universitas Diponegoro.

Ginting, Paham dan Syafrizal Helmi Situmorang. 2008. Filasafat Ilmu dan Metode Riset, Usu Press, Medan

Guritno, Bambang dan Waridin. 2005, "Pengaruh Persepsi Karyawan Mengenai Perilaku Kepemimpinan, Kepuasan Kerja dan Motivasi Terhadap Kinerja". Jurnal Riset Bisnis Indonesia, Vol.1 No.1, p. 63-74

Greenberg, J. \& Baron, R. A . 2003. Behaviour in Organization, Edisi Ke-8, New Jersey : Prentice Hall, Alih Bahasa Agus Maulana. Penerbit Binarupa Aksara. Jakarta.

Handoko T. Hani. 2000. Manajemen Personalia dan Sumberdaya Manusia, Edisi II, Cetakan Keempat Belas, Penerbit BPFE, Yogyakarta 2003. Manajemen Edisi 2, Yogyakarta: BPFE-Yogyakarta.

Hasibuan, S. P. Melayu. 2007. Manajemen Sumber Daya Manusia, Edisi Revisi. Bumi Aksara: Jakarta.

Indriantoro, Nur \& Supomo, Bambang. 2002. Metode Penelitian Bisnis Untuk Akuntansi \& Manajemen, Edisi 1, Yogyakarta : BPFE.

Kartono, Kartini. 2005, Pemimpin dan Kepemimpinan, Jakarta : PT. Raja Grafindo Persada

Luthans, Fred. 2006. Perilaku Organisasi. Yogyakarta : Penerbit ANDI

Mathis, Robert. L, 2000. Manajemen Sumber daya Manusia Jilid 1, Jakarta : Salemba Empat. 
Mahmudi. 2005. Manajemen Kinerja Sektor Publik. Yogyakarta: UPP AMP YKPN

Mangkunegara, A.A. Anwar Prabu. 2005, Manajemen Sumber Daya Manusia Perusahaan, Bandung: Remaja Rosdakarya. 2006. Evaluasi Kinerja Sumber Daya Manusia Perusahaan. Bandung: PT. Refika Aditama.

Mathis Robert L.\& Jackson, John H. 2006, Human Resources Management, Edisi sepuluh, Penerbit Salemba Empat.

Mas'ud, Fuad. 2004, Survai Diagnosis Organisasional : Konsep dan Aplikasi, Badan Penerbit Universitas Diponegoro, Semarang.

Moncrief, W. C., Babakus, E., Cravens, D., Johnston, M. 1997. Examination the Antecedent and Concequences of Salespeoples Job Stress. European Journal of Marketing Examining / Salesperson Job Stress, Vol. 31, No. 11/12, pp. 786-798.

Noor Arifin, 2012." Analisis Kualitas Kehidupan Bekerja, Kinerja, dan Kepuasan Kerja Pada CV Duta Senenan Jepara". Jurnal Economia, Volume 8 No. 1 April 2012.

Robbin, Stephen P. 2003. Perilaku Organisasi. Jakarta : PT Indeks Kelompok Gramedia.

Rivai, Veithza. 2008. Manajemen Sumber Daya Manusia untuk Perusahaan. PT. Raja Grafindo Persada: Jakarta.

Sjafri, Mangkuprawira, Hubeis dan Aida Yitayala. 2007. Manajemen Mutu Sumber Daya Manusia. Bogor: Ghalia Indonesia.

Sedarmayanti. 2009, Sumber Daya Manusia dan Produktivitas Kerja, Bandung: CV. Mandar Maju.

Sopiah. 2008. Perilaku Organisasional, Yogyakarta : penerbit Andi.

Sugiyono. 2005. Metode Penelitian Bisnis. CV Alphabeta, Bandung

Tranggono.R.P \& Kartika.A, 2008. " Pengaruh Komitmen Organisasional dan Professional terhadap Kepuasan Kerja Auditor dengan Motivasi sebagai Variabel Intervening “ (Studi Empiris pada Kantor Akuntan Publik di Semarang), Jurnal Bisnis dan Ekonomi (JBE). Vol.15.No.1.p 80 - 90

Trisnaningsih, S. 2007. Perbedaan Kinerja Auditor Dilihat dari Segi Gender. Jurnal Riset Akuntansi Indonesia

Umar, H. 2005. Metode Penelitian untuk Skripsi dan Tesis Bisnis, Raja Grafindo Persada, Jakarta

Van Scooter, J.R. 2000. "Reltionship of Task Perfioemance and Contextual Performance With Turnover, Job Satisfaction, and Affective Commitment", Human Resource Management Review, 10 (1) : 79-95

Wibowo. 2007. Manajemen Kinerja, PT. Rajagrafindo Persada, Jakarta. 